\title{
DOCTORADO EN HISTORIA CON MENCIÓN EN ESTUDIOS REGIONALES Y LOCALES TRANSDISCIPLINARIOS.
}

\section{LA NUEVA OFERTA ACADÉMICA DEL 2015 DE LA FACULTAD DE HUMANIDADES Y CIENCIAS JURÍDICAS}

Nohemí Rojas Icabalceta

De manera exitosa concluyó el proceso de entrevistas realizadas por la Comisión del Doctorado en Historia, a los postulantes que aplicaron al Doctorado en Historia con mención en estudios regionales y locales transdisciplinarios, que la Facultad de Humanidades y Ciencias Jurídicas de la Universidad Nacional Autónoma de Nicaragua UNAN-Managua ofrece para el 2015.

116 La recepción de la convocatoria, tuvo gran eco en un espectro amplio de personas de diversas formaciones académicas, quienes desde el 24 al 29 de noviembre, se dieron cita a la decanatura de la Facultad de Humanidades y Ciencias Jurídicas, para cumplir con el requisito de la entrevista. El doctorado está programado a comenzar, el próximo 6 de febrero del 2015 teniendo una duración de 3 años, bajo la modalidad de encuentros mensuales.

El programa del Doctorado, tiene la novedad de ser trans disciplinario, enfoque novedoso del curso, lo cual ha motivado a profesionales provenientes de diversas disciplinas del saber, aplicando muchos de ellos. Entre los postulantes que concurrieron a las entrevistas, se encuentran: geógrafos, abogados, historiadores, antropólogos, profesionales del turismo, medioambiente, geólogos, literatos y de otras ciencias sociales. Al finalizar las entrevistas individuales, la Comisión del Doctorado, sesionó de manera ordinaria, con el fin de evaluar

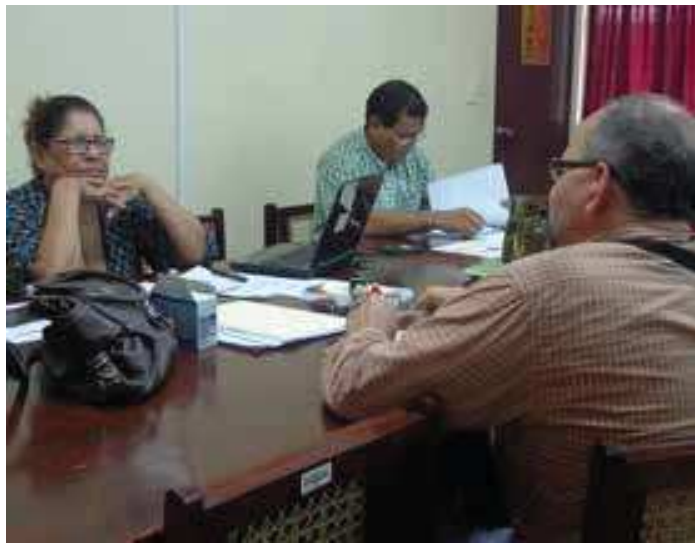

a los postulantes, en base a criterios pres establecidos de pertinencia, viabilidad y solvencia económica. La Comisión conformada por el Doctor. Luis Alfredo Lobato, Presidente, Doctora Jilma Romero Arrechavala, Coordinadora, y los miembros, doctores, Miguel Ayerdis y Edgar Palazio Galo, hicieron la selección de manera imparcial y por medio de actas, dando a conocer los resultados a cada uno de los postulantes, el día 5 de diciembre, cumpliendo de esa manera el cronograma establecido.

La oferta académica del Doctorado en Historia... tiene la pertinencia de brindar oportunidades de ampliación y/o profundización en términos de formación académica especializada a los profesionales, académicos o investigadores que así lo deseen. Además, el enfoque regional y local, 
les brinda herramientas útiles para trabajar con comunidades o colectivos, por medio de proyectos inter y trans disciplinarios, que tengan un impacto positivo en el desarrollo.

La experiencia acumulada en temas de estudios regionales y locales de la Facultad de Humanidades y Ciencias Jurídicas, evidenciada en libros, cursos, y especializaciones, durante más de una década, avalan la solidez de los cursos. Es el primer Doctorado en Historia, y el reto el grande, pero las condiciones y la coyuntura nacional, de promoción del desarrollo y de estabilidad económica, que vive el país, han permitido que este proyecto se realice.

"Nunca Nicaragua estuvo demandando tanto de sus profesionales con una mayor calificación que en este nuevo contexto; es por eso que la UNAN Managua, a través de sus unidades académicas ha querido ofrecer este Doctorado", resaltó la coordinadora del Programa, Dra. Jilma Romero Arrechavala.

El cuerpo de profesores de este doctorado está integrado por profesionales nacionales e internacionales altamente calificados en el campo de la docencia e investigación

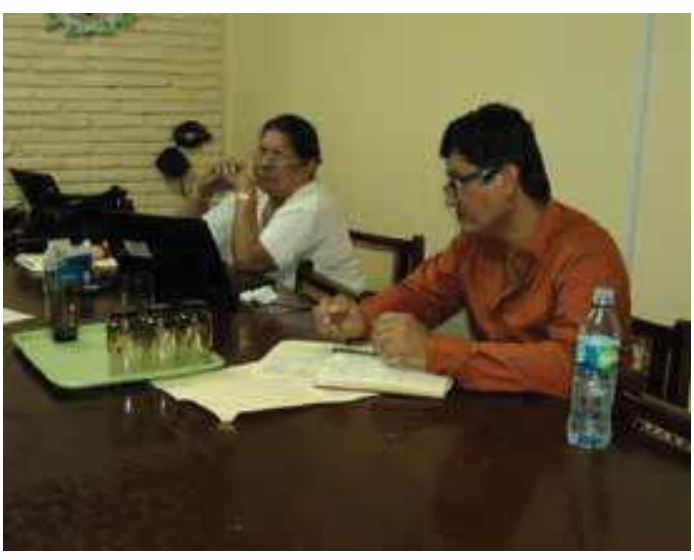

histórica. La selección de estos académicos le da garantía de calidad a los curos que se impartirán. Otro elemento importante, es el componente de investigación que lleva el Doctorado, y estos docente de larga trayectoria en esta área, cierran el perfil del profesional que ha definido el Programa.

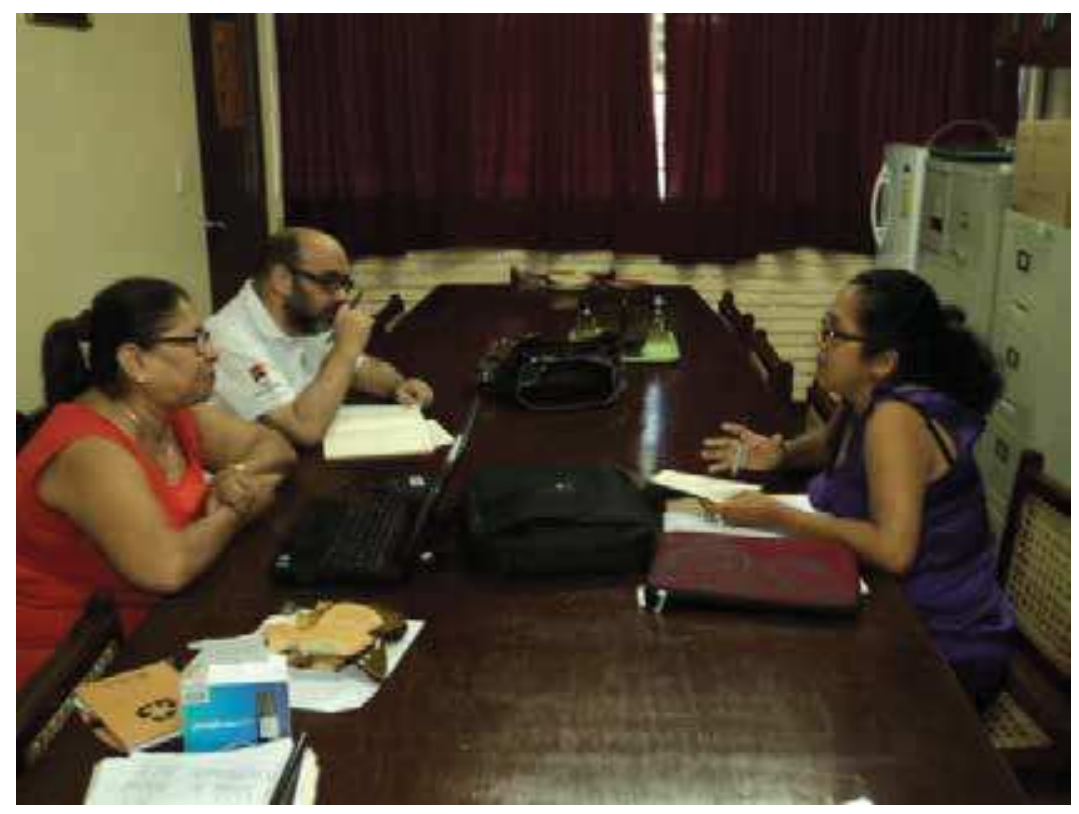

